\title{
HIGHER PREVALENCE OF WATER PIPE COMPARED TO CIGARETTE SMOKING AMONG MEDICAL STUDENTS IN SOUTHEAST IRAN
}

\author{
Masoud Miri-Moghaddam ${ }^{1}$, Mahnaz Shahrakipour², Saeed Nasseri ${ }^{3}$, Ebrahim Miri-Moghaddam ${ }^{4}$ \\ ${ }^{1}$ Student Research Centre, Faculty of Dentistry, Zahedan University of Medical Sciences, Zahedan, Iran \\ ${ }^{2}$ Department of Biostatistics and Epidemiology, Oral and Dental Disease Research Centre, Health Faculty, Zahedan University of Medical \\ Sciences, Zahedan, Iran \\ ${ }^{3}$ Cellular and Molecular Research Centre, Birjand University of Medical Sciences, Birjand, Iran \\ ${ }^{4}$ Department. of Molecular Medicine, Cardiovascular Research Centre, Faculty of Medicine, Birjand University of Medical Sciences, Birjand, Iran
}

\section{SUMMARY}

Objectives: Smoking of water pipe (WP) and cigarettes has recently turned into a major global health burden. The present study aimed at assessing WP and cigarette smoking among Zahedan University of Medical Sciences (ZUMS) students in Iran.

Methods: A cross-sectional survey was conducted on 500 students in ZUMS (182 males, 318 females). The subjects were selected through randomized cluster sampling. Morgan's chart was applied to calculate the sample size; $96.6 \%$ of the attendees completed a questionnaire designed to address the aims of the study.

Results: The mean age of the subjects was $21.2 \pm 2.4$ years. WP and cigarette smoker rates were at $31.2 \%$ and $15.2 \%$, respectively. The age of smoking initiation ranged between 15 and 20 years. Friends played crucial roles in triggering the smoking in both groups of WP and cigarette smokers ( $78 \%$ and $54 \%$, respectively). The main reasons for WP and cigarette smoking were entertainment followed by curiosity. Furthermore, males used more cigarette ( $26.5 \mathrm{vs.} 8.7 \%$ ) and WP (50.6 vs. $20.4 \%$ ) than females. Among father and mother smokers, respectively, $54.2 \%$ and $60 \%$ of children were also WP smokers $(p=0.001)$. Also, $21.9 \%$ and $60 \%$ of children smoking cigarettes had father and mother smokers, respectively $(p=0.05)$.

Conclusion: Tobacco use, especially for WP seems to be at alarming rates among medical students in Iran. It is highly recommended to control the progressive prevalence of WP smoking by governmental/academic preventive measures as educational and smoking cessation activities.

Key words: water pipe, cigarette, smoking, student, university

Address for correspondence: E. Miri-Moghaddam, Cardiovascular Research Centre, Faculty of Medicine, Birjand University of Medical Sciences, Birjand, Iran. E-mail: moghaddam4@yahoo.com

https://doi.org/10.21101/cejph.a5615

\section{INTRODUCTION}

One of the main risk factors associated with health problems is tobacco smoking which remains highly prevalent in different countries (1). According to World Health Organization's (WHO) estimation, current tobacco smokers are more than one billion individuals with mortality rate of approximately five million per year. It is estimated that by the end of 2030 tobacco mediated mortality rate will exceed eight million people (2). It is defined that one water pipe (WP) smoking session involves inhalation of 50-100 times the smoke volume inhaled from a single cigarette. This single water pipe tobacco session may occur in approximately 45 min $(3,4)$. Though risk level of noxious substances depends on the duration of WP session, one time WP smoking gives out the same volume of hazardous chemicals as 100 times cigarette smoking (5). WP smoking, with the history of nearly four centuries, is a kind of smoking in which tobacco smoke passes through water and then is inhaled via a long pipe (6). There is a wrong belief that passage of smoke through water decreases its harmful effects and ingredients in comparison to cigarette smoking.
In fact, this notion has not been supported by recent studies (6). WP smokers are exposed to noxious materials of tobacco smoke as carbon-monoxide $(\mathrm{CO})$, nitric oxide $(\mathrm{NO})$, nicotine, polycyclic aromatic hydrocarbons (PAH), nanoparticles, volatile aldehydes (VAs), and furans (7). As a source of various harmful substances, WP smokers have been shown to be predisposed to a wide range of human disorders. Studies have indicated that complications as unconsciousness and syncope may occur in as much as $20 \%$ of WP smokers (8). Also, long-term WP smoking has been considered as aetiology for secondary polycythaemia (9).

Water pipe smoking acutely decreases heart rate variability (HRV) and elevates CO, plasma nicotine, blood pressure and heart rate. Decrease in HRV predisposes a smoker to the risk of coronary heart disease, mortality, increased systemic inflammation, and arrhythmia. $\mathrm{CO}$ is the predominant noxious gas in tobacco smoke with a much greater binding affinity for haemoglobin than that of oxygen. $\mathrm{CO}$ intoxication is very prevalent in metabolically active organs as the heart and brain $(7,10)$.

Smoking, especially WP, can cause or accelerate the rate of pulmonary and cardiovascular complications as well as cancer 
and new anti-inflammatory drugs with higher specificity and lesser side effects are routinely investigated to elucidate their potential role in curing or decreasing the inflammatory responses in lungs, mediated via cigarette and other stimulatory factors $(11,12)$. Majority of WP smoking mortalities have been reported from developing countries (13). Despite the well-recognized adverse effects of smoking, both WP and cigarette smoking are progressively becoming popular in different societies $(1,14)$. Regarding the prominent role of physicians in providing regular smoking cessation advices to their patients, there are critical concerns about increased prevalence of tobacco consumption among doctors and medical students $(1,15,16)$. As there is no comprehensive data to address the prevalence of WP and cigarette smoking among medical students in this region, we evaluate their prevalence and aetiologies in medical students at Zahedan University of Medical Science in the southeast of Iran.

\section{MATERIALS AND METHODS}

\section{Participants}

In this survey, 500 students enrolled from Zahedan University of Medical Science from 1 October to 30 December 2014. All participants handed in their written informed consent. The sample population was determined according to Morgan's chart. All students (males 182, 36.4\% and females 318, 63.6\%) were healthy. Besides, the study was approved by the Ethics Committee of Zahedan University of Medical Science.

\section{Study Design and Data Collection}

As a cross-sectional survey, a designed questionnaire was given to the participants addressing the following issues related to WP or cigarette smoking: current smoking condition (smoking in the past 30 days), frequency of smoking (defined as number of sessions per day, week, month), common smoking areas, the first smoking age, smoking reasons, tobacco type (flavoured vs. unflavoured), WP duration/session, using a shared/non-shared WP and student's knowledge and attitude toward WTS and cigarette smoking. Addiction to water pipe is not a clear-cut state in literature. However, participants in this survey were asked if they believe on being addicted to water pipe (they are not able to easily quit water pipe smoking). If the participant's answer was positive, we considered him/her as water pipe addict. Questions were designed based on definitions adopted from WHO guidelines. Participant's IDs were anonymous.

\section{Sampling Procedures}

To check the accuracy and reliability of the questionnaire, randomized cluster sampling was applied. In this procedure, each faculty class was considered as a cluster containing 30 subjects. The classes were randomly chosen and the students were given their own questionnaires. The subjects received full explanations regarding the aim of the study. The students' answer sheets were confidentially kept. Cronbach's alpha was calculated as 0.79 .

\section{Statistical Analysis}

The obtained data was analyzed using SPSS software (version: 21). All the measures were expressed as mean \pm standard deviation (SD). P-values $<0.05$ were considered as the significant level. WTS and cigarette smoking were considered as dependent variables.

\section{RESULTS}

\section{Demographic Data}

Five hundred students of different ethnicities (response rate $96.6 \%$ ) participated in the study; $36.4 \%$ were males and $63.6 \%$ females. The overall mean age of participants was $21.2 \pm 2.4$ years. Most of the subjects were single (87.2\%). Sistani ethnicity constituted the majority of the students $(47.3 \%)$, from which $59.7 \%$ resided in dormitories (Table 1 ).

\section{Water Pipe Tobacco and Cigarette Smokers}

Out of 500 study participants, $31.2 \%$ were WP smokers and $15.2 \%$ had the history of cigarette smoking. Compared to the scheduled (daily, weekly, monthly) smoking, irregular smokers served significantly higher rates $(77.3 \%$ and $61.4 \%$, respectively for WP and cigarette smoking). The majority of WP and cigarette smokers had started their first smoking experiences between 15 and 20 years of age either in coffee shops (WP, 65.8\%) or streets (cigarette, $37.9 \%$ ). A significantly large proportion of WP smokers smoked with their friends (78.6\%). Similarly, $54.2 \%$ of cigarette smokers preferred to be with their friends during smoking. Ac-

Table 1. Demographic distribution of participants based on different characteristics $(N=500)$

\begin{tabular}{|c|c|c|c|}
\hline Characteristics & Items & Number & Percentage \\
\hline Mean age & $21.17 \pm 2.4$ & & \\
\hline \multirow{2}{*}{ Gender } & Male & 182 & 36.4 \\
\hline & Female & 318 & 63.6 \\
\hline \multirow{2}{*}{ Marital status } & Single & 436 & 87.2 \\
\hline & Married & 64 & 12.8 \\
\hline \multirow{3}{*}{ Ethnicity } & Sistani & 236 & 47.3 \\
\hline & Balouch & 101 & 20.2 \\
\hline & Others & 163 & 32.5 \\
\hline \multirow{2}{*}{ Residency } & Home (non-campus) & 202 & 40.4 \\
\hline & Campus & 298 & 59.6 \\
\hline \multirow{2}{*}{ Last academic degree } & B.Sc. & 245 & 49.0 \\
\hline & M.D. & 255 & 51.0 \\
\hline \multirow{6}{*}{ Faculty } & Medicine & 161 & 32.2 \\
\hline & Dentistry & 62 & 12.4 \\
\hline & Para medicine & 90 & 18.0 \\
\hline & Nursing & 71 & 14.2 \\
\hline & Health & 56 & 11.2 \\
\hline & Rehabilitation & 60 & 12.0 \\
\hline
\end{tabular}


Table 2. Features related to water pipe and cigarette smoker students (total number: 500, total number of smokers: 232)

\begin{tabular}{|c|c|c|c|}
\hline Variables & Items & $\begin{array}{l}\text { Water pipe smokers (\%) } \\
\qquad(n=156)\end{array}$ & $\begin{array}{l}\text { Cigarette smokers }(\%) \\
\qquad(n=76)\end{array}$ \\
\hline \multirow{4}{*}{ Smoking frequencies } & Daily & 5.5 & 15.9 \\
\hline & Weekly & 8.6 & 9.1 \\
\hline & Monthly & 8.6 & 13.6 \\
\hline & Irregular & 77.3 & 61.4 \\
\hline \multirow{6}{*}{ Smoking places } & Home & 16.2 & 12.1 \\
\hline & Coffee shop & 65.8 & 10.3 \\
\hline & Campus & 1.7 & 12.1 \\
\hline & Friends home & 8.5 & 13.8 \\
\hline & Street & - & 37.9 \\
\hline & Others & 7.7 & 13.8 \\
\hline \multirow{4}{*}{ Initial age of smoking (years) } & $<10$ & 2.0 & 5.6 \\
\hline & $10-14$ & 4.1 & 20.8 \\
\hline & $15-20$ & 58.1 & 47.2 \\
\hline & $>20$ & 35.8 & 26.4 \\
\hline \multirow{3}{*}{ Smoking partner } & Friends & 78.6 & 54.2 \\
\hline & Family & 18.9 & 8.3 \\
\hline & Alone & 2.5 & 37.5 \\
\hline \multirow{7}{*}{ Smoking reasons } & Entertainment & 43.2 & 22.8 \\
\hline & Curiosity & 12.5 & 24.0 \\
\hline & Being with friends & 24.9 & 3.7 \\
\hline & Stress reducing & 3.0 & 20.9 \\
\hline & Enjoyment & 10.6 & 11.1 \\
\hline & Feeling the need & 0.6 & 13.0 \\
\hline & Others & 5.2 & 4.5 \\
\hline
\end{tabular}

cording to the already mentioned questionnaire the most common underlying reason to start smoking WP was entertainment (43.2\%) followed by friend's companionship (24.9\%). However, the same notion was not justified regarding the cigarette smokers (Table 2). Knowledge assessment from non-smokers indicated that health concerns were the fundamental reasons for them to avoid smoking (data not shown). As many as $80.2 \%$ of the students were aware of WP smoking hazards, and acknowledged it was more harmful than cigarette smoking (data not shown).

\section{Smoking Duration}

Furthermore, potential correlation was found between WP smokers and time the students spent to smoke. Results indicated that high proportion of students spent at least one hour smoking (males $81.9 \%$, females $85.7 \%$ ) (Table 3). Data also indicated that the likelihood of using shared WP in both genders $(87.7 \%$ and $77.8 \%$ for males and females, respectively) was higher than in those who did not use a shared one (Table 3).

Fruit flavour was the most interesting tobacco type identified by $97.1 \%$ and $93.5 \%$ of males and females, respectively. Based on questionnaire responses, a significantly high proportion of the current WP smokers (males 89.6\%, females 86.8\%) did not account themselves as WP addicts and claimed to give up their smoking use whenever they wished (males 77.8, females 60.5\%).

\section{Smoker/Non-Smoker Parents}

In general, there was a significant correlation between gender and smoking conditions (Table $4 \mathrm{a}, 4 \mathrm{~b}$ ). In both groups of WP and cigarette smokers, males represented higher proportions compared to females $(50.6 \%$ vs. $20.4 \%$ for WP smoking, and $26.5 \%$ vs. $8.7 \%$ for cigarette smoking, respectively) (Table $4 \mathrm{a}, 4 \mathrm{~b}$ ). In addition, use of WP was associated with ethnicity (Table 4a). Parent's previous addiction was significantly decisive in their offspring's WP and cigarette smoking/non-smoking. Among 156 WP smokers, $54.2 \%$ indicated that their fathers were also WP smokers. A similar proportion (60\%) was confirmed for the WP smokers whose mothers also used WP (Table 4a). However, if the parents do not smoke WP, the percentages of non-smoking children will increase significantly $(71.3 \%$ in cases of non-smoking fathers and $70.8 \%$ of non-smoking mothers). In a similar manner, cigarette smoking parents strongly predisposed their offspring to smoking as $21.9 \%$ of cigarette smokers had smoking fathers. However, the role of mothers was more prominent than fathers. In case of smoking mothers, the proportion almost reached $60 \%$ (Table $4 \mathrm{~b}$ ).

\section{DISCUSSION}

This cross-sectional study was undertaken to evaluate different aspects of WP and cigarette smoking among medical students at 
Table 3. Water pipe smoking among medical students $(N=500)$

\begin{tabular}{|c|c|c|c|}
\hline \multirow{2}{*}{ Variables } & \multirow{2}{*}{ Items } & \multicolumn{2}{|c|}{$\begin{array}{l}\text { Water pipe smokers* } \\
\qquad(n=156)\end{array}$} \\
\hline & & $\begin{array}{l}\text { Males }(\%) \\
(n=92)\end{array}$ & $\begin{array}{c}\text { Females }(\%) \\
\quad(n=64)\end{array}$ \\
\hline \multirow{3}{*}{ Smoking session length } & $<60 \min$ & 81.9 & 85.7 \\
\hline & $60-90 \mathrm{~min}$ & 15.3 & 12.2 \\
\hline & $>90 \mathrm{~min}$ & 2.8 & 2.1 \\
\hline \multirow{4}{*}{ WP smoking in last month } & One time & 51.8 & 41.7 \\
\hline & $2-10$ times & 28.6 & 25.0 \\
\hline & 10-20 times & 16.1 & 30.6 \\
\hline & $>20$ times & 3.6 & 2.8 \\
\hline \multirow{2}{*}{ Using shared WP } & Yes & 87.7 & 77.8 \\
\hline & No & 12.3 & 22.2 \\
\hline \multirow{2}{*}{ Tobacco type } & Simple & 2.9 & 6.5 \\
\hline & Fruity & 97.1 & 93.5 \\
\hline \multirow{2}{*}{ Addiction to WP } & Yes & 10.4 & 13.2 \\
\hline & No & 89.6 & 86.8 \\
\hline \multirow{2}{*}{ Decision to quit } & Yes & 40.7 & 54.3 \\
\hline & No & 59.3 & 45.7 \\
\hline \multirow{3}{*}{ Quit smoking } & Surely, I can & 77.8 & 60.5 \\
\hline & I'm not sure, but I feel that I can & 16.7 & 30.2 \\
\hline & Never & 5.6 & 9.3 \\
\hline
\end{tabular}

${ }^{*}$ Total number of smokers is 232 out of which 156 participants are water pipe smokers.

Table 4a. Relationships between selected demographic characteristics and water pipe and cigarette smoking $(N=500)$

\begin{tabular}{|c|c|c|c|c|c|}
\hline \multirow{2}{*}{\multicolumn{3}{|c|}{ Characteristics }} & \multicolumn{2}{|c|}{ Water pipe use (\%) } & \multirow[b]{2}{*}{$\mathrm{p}$-value } \\
\hline & & & $\begin{array}{c}\text { Yes } \\
(n=156,31.2 \%)\end{array}$ & $\begin{array}{c}\text { No } \\
(n=344,68.8 \%)\end{array}$ & \\
\hline \multicolumn{3}{|l|}{ Mean age } & 21.5 & 21.0 & 0.11 \\
\hline \multirow{2}{*}{ Gender } & \multicolumn{2}{|c|}{ Male } & 50.6 & 49.4 & \multirow{2}{*}{$<0.001$} \\
\hline & \multicolumn{2}{|c|}{ Female } & 20.4 & 79.6 & \\
\hline \multirow{2}{*}{ Marital status } & \multicolumn{2}{|c|}{ Single } & 31.3 & 68.7 & \multirow{2}{*}{0.29} \\
\hline & \multicolumn{2}{|c|}{ Married } & 35.6 & 64.4 & \\
\hline \multirow{3}{*}{ Ethnicity } & \multicolumn{2}{|c|}{ Sistani } & 26.7 & 73.3 & \multirow{3}{*}{0.01} \\
\hline & \multicolumn{2}{|c|}{ Balouch } & 44.4 & 55.6 & \\
\hline & \multicolumn{2}{|c|}{ Others } & 21.6 & 78.4 & \\
\hline \multirow{2}{*}{ Last academic degree } & \multicolumn{2}{|c|}{ B.Sc. } & 33.2 & 66.8 & \multirow{2}{*}{0.65} \\
\hline & \multicolumn{2}{|c|}{ M.D. } & 31.2 & 68.8 & \\
\hline \multirow{2}{*}{ Residency status } & \multicolumn{2}{|c|}{ Home (non-campus) } & 35.4 & 64.6 & \multirow{2}{*}{0.07} \\
\hline & \multicolumn{2}{|c|}{ Campus } & 28.7 & 71.3 & \\
\hline \multirow{8}{*}{ Parental smoking status } & \multirow{2}{*}{$\begin{array}{l}\text { Cigarette smoker } \\
\text { father }\end{array}$} & Yes & 32.4 & 67.6 & \multirow{2}{*}{0.38} \\
\hline & & No & 30.3 & 69.7 & \\
\hline & \multirow{2}{*}{$\begin{array}{l}\text { Cigarette smoker } \\
\text { mother }\end{array}$} & Yes & 60.6 & 30.3 & \multirow{2}{*}{0.17} \\
\hline & & No & 40.0 & 60.0 & \\
\hline & \multirow{2}{*}{ WP smoker father } & Yes & 54.2 & 45.8 & \multirow{2}{*}{$<0.001$} \\
\hline & & No & 28.7 & 71.3 & \\
\hline & \multirow{2}{*}{$\begin{array}{l}\text { WP smoker } \\
\text { mother }\end{array}$} & Yes & 60.0 & 40.0 & \multirow{2}{*}{0.001} \\
\hline & & No & 29.2 & 70.8 & \\
\hline
\end{tabular}


Table 4b. Relationships between selected demographic characteristics and water pipe and cigarette smoking $(N=500)$

\begin{tabular}{|c|c|c|c|c|c|}
\hline \multirow{2}{*}{\multicolumn{3}{|c|}{ Characteristics }} & \multicolumn{2}{|c|}{ Cigarette smoking (\%) } & \multirow[b]{2}{*}{ p-value } \\
\hline & & & $\begin{array}{c}\text { Yes } \\
(n=76,15.2 \%)\end{array}$ & $\begin{array}{c}\text { No } \\
(n=424,84.8 \%)\end{array}$ & \\
\hline \multicolumn{3}{|l|}{ Mean age } & 21.6 & 21.1 & 0.14 \\
\hline \multirow{2}{*}{ Gender } & \multicolumn{2}{|c|}{ Male } & 26.5 & 73.5 & \multirow{2}{*}{$<0.001$} \\
\hline & \multicolumn{2}{|c|}{ Female } & 8.7 & 91.3 & \\
\hline \multirow{2}{*}{ Marital status } & \multicolumn{2}{|c|}{ Single } & 15.0 & 85.0 & \multirow{2}{*}{0.54} \\
\hline & \multicolumn{2}{|c|}{ Married } & 15.3 & 84.7 & \\
\hline \multirow{3}{*}{ Ethnicity } & \multicolumn{2}{|c|}{ Sistani } & 13.7 & 86.3 & \multirow{3}{*}{0.47} \\
\hline & \multicolumn{2}{|c|}{ Balouch } & 14.5 & 45.5 & \\
\hline & \multicolumn{2}{|c|}{ Others } & 8.9 & 91.1 & \\
\hline \multirow{2}{*}{ Grade } & \multicolumn{2}{|c|}{ B.Sc. } & 15.5 & 84.5 & \multirow{2}{*}{0.75} \\
\hline & \multicolumn{2}{|c|}{ M.D. } & 16.3 & 83.7 & \\
\hline \multirow{2}{*}{ Residency status } & \multicolumn{2}{|c|}{ Home (non-campus) } & 11.9 & 88.1 & \multirow{2}{*}{0.06} \\
\hline & \multicolumn{2}{|c|}{ Campus } & 17.3 & 82.7 & \\
\hline \multirow{8}{*}{ Parental smoking status } & \multirow{2}{*}{$\begin{array}{l}\text { Cigarette smoker } \\
\text { father }\end{array}$} & Yes & 21.9 & 78.1 & \multirow{2}{*}{0.02} \\
\hline & & No & 13.2 & 86.8 & \\
\hline & \multirow{2}{*}{$\begin{array}{l}\text { Cigarette smoker } \\
\text { mother }\end{array}$} & Yes & 60.0 & 40.0 & \multirow{2}{*}{0.02} \\
\hline & & No & 14.0 & 86.0 & \\
\hline & \multirow{2}{*}{$\begin{array}{l}\text { WP smoker } \\
\text { father }\end{array}$} & Yes & 24.5 & 75.5 & \multirow{2}{*}{0.05} \\
\hline & & No & 14.4 & 85.6 & \\
\hline & \multirow{2}{*}{$\begin{array}{l}\text { WP smoker } \\
\text { mother }\end{array}$} & Yes & 38.7 & 61.3 & 001 \\
\hline & & No & 13.7 & 86.3 & 0.001 \\
\hline
\end{tabular}

Zahedan University of Medical Science in southeast of Iran. We could find higher rates of WP and cigarette smoking in our cohort compared to similar studies. Besides, significant differences in smoking frequencies among males and females, prominent role of smoking parents, smoking risk factors and predominant pattern of irregular WP smoking were the main findings in the present research. Several pieces of evidence support a growing rate of current smokers among medical students which raises concern about social and individual harmful effects of smoking on their own communities as well as their patients $(1,14,17)$. A self-administrated questionnaire indicated that $23 \%$ of Iranian dental students were current WP or cigarette smokers (16). In our cohort, however, WP and cigarette smoking frequencies were $31.5 \%$ and $15.2 \%$, respectively, and almost $46 \%$ of students had smoked WP at least once in the last month (current smokers). Though WP smoking prevalence seems to be at an alarming rate considering the health-related profession of medical students in this survey, similar studies reported even higher frequencies of WP smoking among Iranian medical students. One study has shown that monthly frequency of WP addicts was almost $60.7 \%$ among Iranian medical students with the current smoking prevalence of $18.7 \%$ (18). A similar study indicated relatively higher rates of current WP smokers (51\%) among health science students (15). On the contrary, medical students smokers comprehensively varied in other countries; tobacco smoking ranged between 3\% for Canadian smokers and $47 \%$ in Greece (19). Current WP student smokers varied from $6 \%$ for the Arab countries to $33 \%$ in Pakistan similar to that of Middle East's adolescent smokers
(6-34\%) $(20,21)$. Alarming rates of tobacco consumptions have been reported worldwide in terms of WP or cigarette smoking, indicating that tobacco usage in general, and WP smoking in particular are progressively becoming a common urban habit (21). According to the World Health Organization, WP smoking is rapidly spreading over South-East Asia, East Mediterranean area and North African territories (22). In our study, the majority of students were irregular smokers $(77.3 \%$ vs. $61.4 \%$ for WP and cigarettes, respectively). In line with these data, predominant pattern of intermittent smoking especially for WP is reported in other studies among college students $(4,23)$. A cross-sectional survey presented more intermittent pattern of WP with a later age of onset, lower interest in quitting and more prevalence among women in part due to wrong perception of minimal risks for WP smoking (4). Smoking is more frequent in males than females which is consistent with our study as males represented profoundly larger population of smokers than females $(\mathrm{p}<0.001)$ $(1,16)$. Male's smoking rate in a meta-analysis has shown to be 8.9 times higher than female's one (11). In some Arab countries, however, studies shed light on new facts as female university students are more interested in WP smoking than males in part due to their traditional beliefs (14). Consistent with other reports, the present study demonstrated that students started cigarette and WP smoking at younger ages (between $15-20$ years) $(3,14,18)$. Immediate preventive measures should be taken into account which necessitates precise investigation of the underlying reasons for approaching smoking at younger ages in Iran. Students who had either cigarette or WP smoking parents had a significantly greater 
chance of being a new smoker. Increased likelihood of finding child smoker in families with smoker parents has been elucidated in several studies $(15,24)$. Though contradictory, it is shown that smoking parents play a pivotal role in increasing the possibility of tempting their children to start smoking (19). It is worth noting that maternal smoking and the parent-child communication quality may influence the current smoking situation of their kids and students who lived away from their non-smoking parents and are more vulnerable to be either current cigarette or WP smokers (25). Surveys conducted among Arab-American high school students indicated that adolescents would 6.3 times more likely be current WP smokers if one or more family members smoked WP at home (26). These findings accentuate the potential role of parents in minimizing the risk for their children to become new smokers.

Entertainment, friend's companionship and getting rid of stress where mentioned as the main reasons to start WP smoking by our participants. One survey identified lack of entertainment and stressful lifestyle as the primary reasons among medical students to surge WP smoking (27). Another cross-sectional study among dental students reported that half of the current smokers accounted stress as the main reason to smoke (1). Indeed, stress has been identified as the main barrier for physicians to quit smoking and entertainment, fun, and enjoyment has been mentioned as the main incentives to initiate WP smoking among other medical students $(15,18,28,29)$.

It is worth noting that 500 participants from different medical majors were the strength of our study. Furthermore, a comprehensive questionnaire which covers almost all aspects of their daily life was another positive point of this survey. Nonetheless, one limitation of this survey was the fact that we did not considered health risk factors related to smoking including respiratory complications they may ever experienced. We have speculated that people may consider these questions as private health issues. Another impediment was respondents obtained from only one university and thus these results cannot be perceived as representative for all medical students in Iran.

Taking into consideration these data, the increasing rate of current WP smoking among Iranian medical students has a pivotal implication: as medical apprentices with greater knowledge about the hazards of WP smoking, they may adversely affect the public health and education during their careers. Yet, all medical students should be aware of the health hazards related to smoking. Using systematic and comprehensive schedules, efforts should be made to promote smoking cessation programmes in medical practice settings. These programmes should cover all aspects of student's life as emotional, mental and social issues. Accordingly, policy makers should consider these issues as imperative factors in their decisions for decreasing or preventing of smoking among university students.

\section{CONCLUSION}

It can be concluded, in view of the present study, that the prevalence of smoking especially WP smoking reached quite high rates among medical students in Iran. Furthermore, higher incidence of current WP and cigarette smokers, smoking irregular patterns, greater proportion of smoking males compared to females, lower smoking ages, provocative role of smoker parents, and prominent smoking risk factors were evaluated in this report and approved by previous investigations. These pieces of evidence have served as an alarming message for Iranian public health authorities and should be monitored by policy-makers.

\section{Acknowledgements}

The authors would like to thank the students who participated in the research. The current research was funded by the Research Deputy of Zahedan University of Medical Sciences under the grant number 6698.

\section{Conflict of Interests}

None declared

\section{REFERENCES}

1. AlSwuailem AS, AlShehri MK, Al-Sadhan S. Smoking among dental students at King Saud University: Consumption patterns and risk factors. Saudi Dent J. 2014 Jul;26(3):88-95.

2. MPOWER: a policy package to reverse the tobacco epidemic. Geneva: WHO; 2008.

3. Khabour OF, Alzoubi KH, Eissenberg T, Mehrotra P, Azab M, Carrol MV. Waterpipe tobacco and cigarette smoking among university students in Jordan. Int J Tuberc Lung Dis. 2012 Jul;16(7):986-92.

4. Maziak W, Eissenberg T, Ward KD. Patterns of waterpipe use and dependence: implications for intervention development. Pharmacol Biochem Behav. 2005 Jan;80(1):173-9.

5. WHO report on the global tobacco epidemic, 2008: the MPOWER package. Geneva: WHO; 2008.

6. Alvur MT, Cinar N, Akduran F, Dede C. Fallacies about water pipe use in Turkish university students - what might be the consequences? Asian Pac J Cancer Prev. 2014;15(5):1977-80.

7. Cobb CO, Sahmarani K, Eissenberg T, Shihadeh A. Acute toxicant exposure and cardiac autonomic dysfunction from smoking a single narghile waterpipe with tobacco and with a "healthy" tobacco-free alternative. Toxicol Lett. 2012 Nov 23;215(1):70-5.

8. von Rappard J, Schönenberger M, Bärlocher L. Carbon monoxide poisoning following use of a water pipe/hookah. Dtsch Arztebl Int. 2014 Oct 3;111(40):674-9.

9. Miri-Moghaddam E, Mirzaei R, Arab MR, Kaikha S. The effects of water pipe smoking on hematological parameters in rats. Int J Hematol Oncol Stem Cell Res. 2014 Jul 1;8(3):37-43.

10. Karaca Y, Eryigit U, Aksut N, Turkmen S. Syncope associated with water pipe smoking. BMJ Case Rep. 2013 Apr 19;2013. pii: bcr2013009526.

11. Nasseri S, Gurusamy M, Jung B, Lee D, Khang G, Doods H, et al. Kinin B1 receptor antagonist BI113823 reduces acute lung injury. Crit Care Med. 2015 Nov;43(11):e499-507.

12. Gurusamy M, Nasseri S, Lee H, Jung B, Lee D, Khang G, et al. Kinin B1 receptor antagonist BI113823 reduces allergen-induced airway inflammation and mucus secretion in mice. Pharmacol Res. 2016 Feb;104:132-9.

13. Maziak W, Ward KD, Afifi Soweid RA, Eissenberg T. Tobacco smoking using a waterpipe: a re-emerging strain in a global epidemic. Tob Control. 2004 Dec;13(4):327-33.

14. Maziak W, Eissenberg T, Rastam S, Hammal F, Asfar T, Bachir ME, et al. Beliefs and attitudes related to narghile (waterpipe) smoking among university students in Syria. Ann Epidemiol. 2004 Oct;14(9):646-54.

15. Ghafouri N, Hirsch JD, Heydari G, Morello CM, Kuo GM, Singh RF. Waterpipe smoking among health sciences university students in Iran: perceptions, practices and patterns of use. BMC Res Notes. 2011 Nov 16;4:496. doi: 10.1186/1756-0500-4-496.

16. Khami MR, Murtomaa H, Razeghi S, Virtanen JI. Smoking and its determinants among Iranian dental students. Med Princ Pract. 2010;19(5):3904.

17. Jackson D, Aveyard P. Waterpipe smoking in students: prevalence, risk factors, symptoms of addiction, and smoke intake. Evidence from one British university. BMC Public Health. 2008 May 22;8:174. doi: 10.1186/1471-2458-8-174

18. Sabahy AR, Divsalar K, Bahreinifar S, Marzban M, Nakhaee N. Waterpipe tobacco use among Iranian university students: correlates and perceived reasons for use. Int J Tuberc Lung Dis. 2011 Jun;15(6):844-7. 
19. Mandil A, BinSaeed A, Ahmad S, Al-Dabbagh R, Alsaadi M, Khan M. Smoking among university students: a gender analysis. J Infect Public Health. 2010 Dec;3(4):179-87.

20. Akl EA, Gunukula SK, Aleem S, Obeid R, Jaoude PA, Honeine R, et al. The prevalence of waterpipe tobacco smoking among the general and specific populations: a systematic review. BMC Public Health. $2011 \mathrm{Apr}$ 19;11:244. doi: 10.1186/1471-2458-11-244.

21. Maziak W. The global epidemic of waterpipe smoking. Addict Behav. 2011 Jan-Feb;36(1-2):1-5.

22. WHO Study Group on Tobacco Product Regulation. Advisory note: waterpipe tobacco smoking: health effects, research needs and recommended actions by regulators [Internet]. Geneva: WHO; 2005 [cited 2019 Aug 14]. Available from: https://www.who.int/tobacco/global_interaction/ tobreg/Waterpipe\%20recommendation Final.pdf.

23. Almerie MQ, Matar HE, Salam M, Morad A, Abdulaal M, Koudsi A, et al. Cigarettes and waterpipe smoking among medical students in Syria: a cross-sectional study. Int J Tuberc Lung Dis. 2008 Sep;12(9):1085-91.

24. Bejjani N, El Bcheraoui C, Adib SM. The social context of tobacco products use among adolescents in Lebanon (MedSPAD-Lebanon). J Epidemiol Glob Health. 2012 Mar;2(1):15-22.

25. Kandel DB, Wu P, The Contributions of mothers and fathers to the intergenerational transmission of cigarette smoking in adolescence. $\mathrm{J}$ Res Adolesc. 1995;5(2):225-52
26. Alzyoud S, Weglicki LS, Kheirallah KA, Haddad L, Alhawamdeh KA. Waterpipe smoking among middle and high school Jordanian students: patterns and predictors. Int J Environ Res Public Health. 2013 Dec 12;10(12):7068-82.

27. Jawaid A, Zafar AM, Rehman TU, Nazir MR, Ghafoor ZA, Afzal O, et al Knowledge, attitudes and practice of university students regarding waterpipe smoking in Pakistan. Int J Tuberc Lung Dis. 2008 Sep;12(9):1077-84.

28. Newbury-Birch D, Lowry RJ, Kamali F. The changing patterns of drinking, illicit drug use, stress, anxiety and depression in dental students in a UK dental school: a longitudinal study. Br Dent J. 2002 Jun 15;192(11):646-9.

29. Roohafza H, Sadeghi M, Shahnam M, Bahonar A, Sarafzadegan N. Perceived factors related to cigarette and waterpipe (ghelyan) initiation and maintenance in university students of Iran. Int J Public Health. 2011 Apr;56(2):175-80.

Received March 28, 2018 Accepted in revised form August 14, 2019 